\title{
THE LAW IN THE INFORMATION AND RISK SOCIETY ${ }^{*}$ Gunnar Duttge, Sang Won Lee (Dir.), UNIVERSITÄTSVERLAG GötTINGEN, 2011
}

Myriam Denieul** $^{* *}$

Novas doenças, novas tecnologias e novos meios de comunicação: em poucos anos, nossas sociedades têm enfrentado desafios e mudanças importantes que as conduziram ao próprio remodelamento. Por um lado, assistimos ao nascimento de uma "sociedade de risco", expressão popularizada pelo sociológo alemão Ulrich Beck ${ }^{(1)}$; por outro lado, o surgimento da "sociedade da informação", caracterizada pelo desenvolvimento do conhecimento e dos meios de comunicação. Qual deve ser o papel do direito diante dessas transformações? Esse é o assunto da obra coletiva The Law in the Information and Risk Society, resultado de uma conferência organizada pela Universidade de Göttingen em maio de 2011. Relacionadas a esse tema, diversas áreas do direito são tratadas nessa obra, tais como assuntos de direito comercial (Contract Law, Industrial Law e Governing Stock), propriedade intelectual e de novas tecnologias (Internet Law e Intellectual Property) e direito criminal (Criminal Law e Criminology). A parte que se relaciona mais diretamente ao direito sanitário, o objeto da presente resenha, é a sessão dedicada aos aspetos de direito constitucional, à legislação sobre o sigilo de dados e ao direito médico (Constitutional Principles, Data Privacy e Medical Law).

Se o conteúdo dessa parte pode parecer a priori heteróclito, na verdade podemos classificar os temas abordados em duas categorias, seguindo diretrizes do direito sanitário: em primeiro lugar, os riscos relacionados às autoridades públicas e, em segundo lugar, os riscos relacionados aos cidadãos.

( $\left.{ }^{\star}\right)$ Disponível para download gratuito em: <http://www.oapen.org/search?identifier=400092;keyword= health>.

$\left.{ }^{\star \star *}\right)$ Doutoranda em Direito Privado, Université Paris Descartes; Mestre em Direito Sanitário, Université Paris Descartes; Mestre em Direito Econômico, Institut d'Etudes Politiques de Paris (Sciences po). Paris - França. E-mail: myriam.denieul@gmail.com.

Texto recebido em 30.09.12. Aprovado em 10.10.12.

(1) BECK, Ulrich. Sociedade de risco: rumo a outra modernidade. Tradução: Sebastião Nascimento. 1. ed. São Paulo: Ed. 34, 2010. 


\section{O PAPEL DAS AUTORIDADES PÚBLICAS NA SOCIEDADE DE RISCO E DA INFORMAÇÃO}

A primeira pergunta que se destaca em relação à apreensão dos riscos é a questão do ator privilegiado na sociedade de risco: o poder público é preferível aos atores do mercado? Quais são a legitimidade e os limites da atuação desses últimos?

\section{O PAPEL PRIVILEGIADO DO GOVERNO NA GESTÃO DOS RISCOS (WERNER HEUN)}

O estudo de Werner Heun destaca as razões pelas quais o governo desempenha um papel primordial na sociedade de risco. Em primeiro lugar, o autor explica as diferenças entre os conceitos de segurança, de perigo e de risco, que são frequentemente confundidos. Na teoria política e constitucional, "segurança" é o termo mais antigo: vem da ideia de securitas romana, que se refere à ausência de sofrimento e de distúrbio. Com o desenvolvimento dos estados modernos, a securitas publica se tornou o objetivo central da atuação pública, e o sentido de "segurança" se desenvolveu, até incluir a ideia de "securidade social" no século 19. Na Alemanha, o perigo (Gefahr), que constitui uma ameaça à segurança, é também um conceito do século 19. Essa noção vem do direito administrativo prussiano e continua a ser aplicada hoje: refere-se a uma situação ou condição na qual, caso não corrigida, uma circunstância ou conduta causará prejuízo à segurança pública com um certo grau de probabilidade. Comparado aos termos de segurança e perigo, o conceito de risco é relativamente recente na jurisprudência alemã. Esse termo se desenvolveu principalmente em relação aos riscos técnicos e se refere à combinação da probabilidade de ocorrência de um evento perigoso com a gravidade do dano que pode resultar.

A pergunta central deste artigo é: quem deve lidar com os riscos na sociedade de risco e da informação? O autor desenvolve as razões pelas quais a gestão dos riscos pelo setor privado não é adequada. De fato, a teoria econômica mostra que existem deficiências do mercado, tais como assimetrias de informação, riscos morais, incertezas ou externalidades, que limitam a eficiência do setor privado. Ademais, existe um dilema ligado à capacidade e à probabilidade de resposta do governo em um caso de perigo: sabendo com grande certeza que o governo vai agir, os atores privados parecem menos preocupados com problemas de segurança. Estudos revelam que a percepção e a gestão dos riscos nem sempre são racionais. Pessoas têm mais receio de riscos que parecem fora de controle, sejam individuais, sejam coletivos ${ }^{(2)}$. Por exemplo, a aceitação dos riscos é maior quando resultam de uma ação puramente voluntária (cigarros) do que quando vêm a ser impostos por terceiros (aditivos nos alimentos).

(2) SLOVIC, Paul. The perception of risk. Londres: Earthscan, 2000. 
Em um sistema de mercado, adotado pela maioria dos países ocidentais, o poder público tem a missão de compensar as situações em que o mercado não funciona. Isso resulta no papel "natural" do governo na gestão última dos riscos. Diferentes métodos podem ser utilizados por ele para modificar ou moderar riscos: (1) prevenção/redução dos riscos através de leis criminais ou regras de segurança, (2) relocação/redistribuição dos riscos graças a leis de responsabilidade ${ }^{(3)}$ ou contratos e (3) repartição/mutualização dos riscos através de seguros obrigatórios.

Um aspecto importante e não abordado no artigo analisado é a ligação entre a legitimidade de atuação do Estado no campo dos riscos e a capacidade do seu conhecimento, que depende do desenvolvimento dos saberes científicos químicos e biológicos. Antes do século 19, a segurança dos alimentos era autorregulada pelos atores privados: o poder público não tinha, com efeito, nenhuma capacidade superior aos consumidores vigilantes para controlar a salubridade de um produto( ${ }^{(4)}$. Graças aos avanços científicos no último século, o Estado tem desenvolvido, através da criação de agências, um grau de expertise e de capacidade burocrática e administrativa que, para os atores privados, se tornou impossível atingir. Isso justifica o papel privilegiado do poder público na gestão, avaliação e comunicação dos riscos.

\section{EQUILÍBRIO DOS PODERES EM TEMPOS DE CRISE (HONG SIK CHO)}

Se o Poder Executivo parece um ator essencial na sociedade de risco, qual deve ser o equilíbrio entre os diferentes poderes? Será que os controles e as responsabilidades do governo e do parlamento (o sistema de check and balances) devem ser modificados em tempos de crise?

Após os ataques de 11 de setembro de 2001, o mundo anglo-saxônico desenvolveu um novo interesse pelo trabalho de Carl Schmitt. Além de influenciar o pensamento político e jurídico alemão, esse jurista é conhecido por causa da sua ligação com o regime nazista. A tese principal de Schmitt é, de fato, uma crítica ao liberalismo: ele demonstra as contradições do Estado liberal, especialmente em "tempos de exceção". Visto que tempos de crise criam desafios particulares, este artigo trata da questão da extensão de poderes que o dirigente deve ser capaz de exercer nesses tempos especiais, à luz do pensamento de Carl Schmitt. A pergunta é como lidar com um choque tão importante em que as regras normais do sistema político não parecem ser mais aplicáveis. No âmbito da saúde pública, certas crises, tais como epidemias, podem conduzir o governo a agir de forma específica.

(3) É importante destacar que as regras de responsabilidade têm também uma função preventiva: elas influenciam o comportamento dos atores e podem conduzir à redução de comportamentos de risco, portanto, de danos.

(4) FERRIERES, Madeleine. Histoire des peurs alimentaires: du Moyen Age à l'aube du 20e siècle. Paris: Seuil, 2002. 
O antiliberalismo de Schmitt suscita um eco em tempo de emergências. Segundo ele, para superar crises, alguém tem que tomar decisões de maneira livre e, por isso, o dirigente deve ter a possibilidade de exercer uma soberania política sem restrições, em detrimento do controle parlamentar. Essa teoria de "medidas excepcionais para tempos excepcionais" pode prejudicar a separação dos poderes, assim como os direitos individuais, e existe um risco intrínseco de abuso desse poder pelo dirigente. Faz-se assim necessária a implementação de um controle ex post facto das decisões do dirigente. Mesmo que essa solução seja criticada, porque ela pode normalizar e legitimar a posteriori estados de exceção e conduzir a uma "emergência permanente", o autor afirma que isso é um "mal menor": o pior seria aceitar o caráter derrogatório das situações de emergência e dos estados de exceção e deixá-los fora de qualquer controle.

A distinção entre os diferentes tipos de crises suscetíveis de resultar em um "estado de exceção" é um assunto ausente neste artigo. Segundo Schmitt, a decisão deve superar a discussão no processo político, mas seria interessante destacar que uma crise sanitária, uma crise financeira ou uma ameaça terrorista não levantam os mesmos problemas em termos de governança. Para lidar com a maioria das crises sanitárias, o dirigente precisa de uma importante expertise para tomar decisões e, na maioria dos casos, vai seguir as recomendações das agências nacionais ou internacionais. Isso leva a outra questão essencial relacionada à legitimidade e responsabilidade dessas instituições.

\section{O CONTROLEEFETIVO DAATUAÇÃO DO GOVERNO PELO PARLAMENTO (FRANK SCHORKOPF)}

$\mathrm{Na}$ área da cooperação política internacional, a informação está no coração do controle da atuação dos governos pelos parlamentos nacionais. O tema do artigo de Frank Schorkopf é a regulação da comunicação de informações, o que constitui um dos maiores desafios para a construção do direito internacional e regional.

O Parlamento Alemão (Bundestag) tem o direito constitutional de se pronunciar sobre uma questão antes de o governo participar na elaboração de um ato legislativo da União Europeia. O direito europeu também prevê o envolvimento dos parlamentos nacionais no controle do exercício das competências da União. Para garantir a efetividade desses direitos, a lei fundamental alemã afirma que o governo deve relatar ao Bundestag de forma aprofundada e o mais rapidamente possível(5).

(5) Artigo 23 (2) da Lei fundamental, completado por uma lei que regulamenta detalhes sobre o dever de informação (Gesetz über die Zusammenarbeit von Bundesregierung und Deutschen Bundestag in Angelegenheiten der Europäischen Union). 
O problema central é a classificação e a seleção da informação a ser transmitida aos parlamentos, ou seja, a quantitade adequada e pertinente de peças que devem ser transferidas diariamente. É importante destacar que, ao trabalho de controle, se acrescentam as obrigações tradicionais dos parlamentares nacionais, enquanto a produção legislativa nacional não diminui por causa da integração europeia ${ }^{(6)}$. Um aspecto importante dessa questão que não é abordado neste artigo é a complexidade e a tecnicidade das informações sobre as quais muitas regulamentações se baseiam e, portanto, a dificuldade para parlamentares exercerem um controle efetivo. Grupos de expertise internos aos parlamentos seriam uma opção interessante, mas as capacidades destes parecem limitadas diante das numerosas regulamentações. Assim, o paradoxo da sociedade de informação é que os conhecimentos podem ser acessíveis facilmente, mas dificilmente entendidos.

Se as questões de legitimidade, de controle e de expertise ficam no centro da atuação do poder público na sociedade de risco e de informação, as perspectivas e as preocupações diferem quando consideramos o ponto de vista dos cidadãos.

\section{A PROTEÇÃO DOS CIDADÃOS NA SOCIEDADE DE RISCO E INFORMAÇÃO}

A proteção do indivíduo, quer seja em face dos interesses de outros indivíduos, quer seja em face do bem comum, é também um objetivo do direito na sociedade de risco e informação.

\section{A AUTONOMIA DO INDIVÍDUO E OS LIMITES DO DIREITO À INFORMAÇÃO (GUNNAR DUTTGE)}

"Quanto mais sabemos, mais podemos." As ideias de que conhecimento é poder e de que a sabedoria é libertadora têm influenciado consideravelmente a prática da medicina e do direito sanitário, promovendo a tese segundo a qual um papel de maior importância deve ser atribuído à informação. Isso se traduziu, por exemplo, na exigência de um "consentimento informado/esclarecido" do paciente na escolha das opções terapêuticas e das decisões relativas à sua saúde e nas especificações relativas à rotulagem de medicamentos, cuja formulação deve ficar compreensível e legível ao consumidor. No entanto, se a importância da informação no âmbito do direito sanitário não pode ser negada, este artigo levanta a questão da existência de um "direito à ignorância" em certos casos.

(6) Ao contrário, os Estados-Membros agora têm que se conformar com diretivas e exigências europeias. Isso explica a sobrecarga do Bundestag (parlamento alemão) e de outros parlamentos nacionais. 
Diagnósticos genéticos podem criar tensões entre o direito do individuo à privacidade, à autodeterminação e aos interesses das pessoas potencialmente afetadas pelo resultado do teste (principalmente os parentes). A lei alemã de fevereiro de 2010 sobre os diagnósticos genéticos afirma que "ninguém deveria ser informado sobre as suas disposições genéticas contra a sua vontade ou [...] ter que tolerar tal restrição ao desenvolvimento da sua personalidade". A lei não prevê uma notificação dos parentes a respeito dos resultados de testes genéticos, mas, caso as características genéticas revelem uma doença evitável ou tratável, o profissional de saúde deve recomendar à pessoa examinada que informe seus parentes a fim de que eles passem por consultas médicas e verifiquem a possibilidade de ocorrência dessa doença.

Existem outras áreas do direito médico nas quais o direito à ignorância pode ser aplicável. Por exemplo, os testes efetuados em uma pessoa sem o seu próprio consentimento para detectar uma doença (como a HIV/Aids) são proibidos, assim como a divulgação dos resultados. De fato, esse tipo de prática constitui uma transgressão da integridade do indivíduo e uma violação do seu direito à autodeterminação. Ao contrário, em situações nas quais existe uma ameaça iminente para outras pessoas, como no caso de epidemias de doenças infecciosas, admite-se que seja dada prioridade às considerações de saúde pública e do bem comum sobre o direito à ignorância de um indivíduo.

Na contramão da ideia predominante da sociedade de informação, segundo a qual mais conhecimento só pode ser positivo, a conclusão do autor deste artigo é muito interessante. Citando Hans Jonas, de acordo com quem "incerteza é um pré-requisito à liberdade", ele afirma que ignorância pode fazer parte da sabedoria e do bom senso humano. Não se deve esquecer que a fundamentação do direito à informação é o respeito da autonomia do individuo; assim, a supremacia da autonomia pode justificar, em certos casos, o direito à ignorância. Todavia, esse direito não deve se tornar na área médica uma justificativa para deixar todas as decisões nas mãos dos profissionais de saúde. A medicina moderna, sob a influência do direito médico, distanciou-se da abordagem paternalista na qual o médico velava pelo bem-estar de seu paciente sem deixá-lo tomar decisões. Agora que o paciente se tornou o ator principal de sua saúde, é preciso que o reconhecimento do direito à ignorância acompanhe uma definição e uma regulamentação das situações nas quais esse direito for aplicável, para não conduzir a uma prática retrógrada.

\section{A PROTEÇÃO DO INDIVÍDUO SUJEITO A PESQUISAS (ERWIN DEUTSCH)}

A proteção do indivíduo perante o bem comum é um ponto fundamental na sociedade de risco. Baseando-se nas pesquisas sobre vacinas, este artigo levanta a questão do equilíbrio entre o respeito ao paciente de pesquisas e os interesses coletivos ligados às experimentações e aos progressos médicos. Pesquisas sobre vacinas envolvem questões éticas e legais importantes, pois a saúde e o bem-estar dos participantes podem entrar em conflito com os objetivos da pesquisa. 
O exemplo histórico da pesquisa da vacina contra a varíola, que foi relatada por Voltaire nos Lettres anglaises, envolveu presos da cadeia de Newgate em Londres que receberam a oportunidade de participar de um programa de inoculação do vírus da varíola em troca de serem libertados. Essa experiência foi um sucesso e resultou na popularidade da vacina contra a varíola na Inglaterra, mas exemplifica também a dificuldade perpétua em se achar pessoas que se sujeitem às pesquisas, devido aos riscos associados às experimentações. Nos últimos anos, casos de morte de indivíduos na primeira fase ${ }^{(7)}$ da pesquisa clínica têm lembrado que, se as pesquisas de vacinas são, sem dúvida, necessárias, elas podem também se tornar perigosas para os pacientes.

Para proteger os pacientes sujeitos à experimentação, regras jurídicas se baseiam em dois "pilares": a justificativa médica da pesquisa e o consentimento informado do paciente. $\mathrm{O}$ indivíduo deve ser informado dos objetivos, dos métodos, benefícios e riscos ligados à pesquisa. Por isso, pesquisas clínicas em grupos mais vulneráveis da população (crianças ou pessoas com doença mental) são proibidas de forma geral, devido à inabilidade destes em consentir com a pesquisa em $\mathrm{si}^{\left({ }^{(8)}\right.}$. Ademais, no caso de um acidente ligado à experimentação, a vítima deve receber compensação sem ter que provar nenhuma culpa ou negligência ${ }^{(9)}$. Essa regra resulta do fato de que o sujeito da pesquisa aceitou arriscar ou, às vezes, "sacrificar" a sua saúde em prol do interesse geral.

Interessante é a questão da aplicação dessas regras em situações grandiosas, como em casos de guerra. A operação Desert Storm ilustra isso: durante a primeira Guerra do Golfo, os Estados Unidos temeram a utilização pelo inimigo de armas químicas e biológicas. O Departamento de Defesa dos Estados Unidos solicitou a autorização da agência de regulação sanitária norte-americana (Food and Drug Administration - FDA), para usar medicamentos e vacinas ainda não aprovados. Devido à "necessidade militar" e ao perigo real e imediato enfrentado pelos soldados, a FDA autorizou o uso destes. Além de guerras, é importante destacar que existem outras situações nas quais as regras podem ser flexibilizadas, como no caso de uma epidemia ameaçando a população. A necessidade de estabelecer um compromisso entre os interesses individuais e o interesse coletivo pode conduzir, nesses casos específicos, à adoção de soluções divergentes do que as que prevaleceriam nas situações normais.

(7) Pesquisas de fase I têm o objetivo de determinar a segurança da vacina. Se for reconhecida como segura durante esta primeira fase, sua eficácia será testada nas três fases posteriores.

(8) Todavia, experiências devem ser autorizadas em certos casos, quando uma doença diz respeito diretamente a um destes grupos (tipicamente, uma doença infantil).

(9) Para a proteção dos sujeitos de pesquisas, a lei alemã prevê o instrumento do seguro. Já a lei francesa aplica a responsabilidade objetiva (que significa que nem a culpa nem a negligência são relevantes) nos casos de acidentes nas experimentações. 


\section{CONSIDERAÇÕES FINAIS}

Qual deve ser o papel do direito na sociedade de risco e informação? Essa obra coletiva ilustra perfeitamente que nesse contexto as regras jurídicas têm uma missão de regulação, buscando equilíbrio entre interesses divergentes.

É interessante destacar que, por causa das numerosas incertezas acerca dos riscos emergentes (biotecnologias ou nanotecnologias, por exemplo), o indivíduo volta a ser considerado um ator central da regulação dos riscos, em face de um Estado que deixou de ser onisciente e visionário ${ }^{(10)}$. Nesse contexto, o questionamento profundo sobre a capacidade de governança das nossas sociedades deve ser acompanhado, segundo Christine Noiville, de uma mudança na nossa relação com os riscos e na responsabilidade dos indivíduos ${ }^{(11)}$. Parece assim que a evolução constante da sociedade de risco e informação faz o direito evoluir ao mesmo tempo.

\section{REFERÊNCIAS}

BECK, Ulrich. Sociedade de risco: rumo a outra modernidade. Tradução: Sebastião Nascimento. 1. ed. São Paulo: Ed. 34, 2010.

BORRAZ, Olivier. Les politiques du risque. Paris: Presses de Sciences Po, 2008. FERRIERES, Madeleine. Histoire des peurs alimentaires: du Moyen Age à l'aube du 20e siècle. Paris: Seuil, 2002.

NOIVILLE, Christine. Du bon gouvernement des risques. Paris: PUF, 2003.

SLOVIC, Paul. The perception of risk. Londres: Earthscan, 2000.

(10) BORRAZ, Olivier. Les politiques du risque. Paris: Presses de Sciences Po, 2008.

(11) NOIVILLE, Christine. Du bon gouvernement des risques. Paris: PUF, 2003. 